\title{
A Mathematical Model for Minimizing Add-On Operational Cost in Electrical Power Systems Using Design of Experiments Approach
}

\author{
Zakaria Al-Omari*, A. Hamzeh*, Sadeq A. Hamed*, A. Sandouk ${ }^{* *}$, G. Aldahim ** \\ * Electrical Engineering Department, Faculty of Engineering, Al-Ahliyya Amman University, Jordan \\ ** Electrical Power Engineering Department, Damascus University, Jordan
}

\begin{tabular}{l} 
Article Info \\
\hline Article history: \\
Received May 12, 2015 \\
Revised Jul 15, 2015 \\
Accepted Jul 28, 2015 \\
\hline
\end{tabular}

\section{Keyword:}

Add-on operational costs

Power system losses

Regression statistical analysis

Tap-changer settings

\begin{abstract}
One of the key functions of the Distribution System Operators (DSOs) of electrical power systems (EPS) is to minimize the transmission and distribution power losses and consequently the operational cost. This objective can be reached by operating the system in an optimal mode which is performed by adjusting control parameters such as on-load tap changer (OLTC) settings of transformers, generator excitation levels, and VAR compensators switching. The deviation from operation optimality will result in additional losses and additional operational cost of the power system. Reduction of the operational cost increases the power system efficiency and provides a significant reduction in total energy consumption. This paper proposes a mathematical model for minimizing the additional (add-on) costs based on Design of Experiments (DOE). The relation between add-on operational costs and OLTC settings is established by means of regression statistical analysis. The developed model is applied to a 20 -bustest network. The regression curve fitting procedure requires simulation experiments which have been carried out by the DigSilent PowerFactory 13.2 Program for performing network power flow. The results show the effectiveness of the model. The research work raises the importance the power system operation management of the EPS where the Distribution System Operator can avoid the add-on operational costs by continuous correction to get an operation mode close to optimality.
\end{abstract}

Copyright (C) 2015 Institute of Advanced Engineering and Science. All rights reserved.

\section{Corresponding Author:}

Zakaria Al-Omari,

Electrical Engineering Departement, Faculty of Engineering, Al-Ahliyya Amman University, Al-Ahliyya Amman University Post Office, Zip code 19328 (Amman Jordan).

Email: alomari_zakaria@yahoo.com

\section{INTRODUCTION}

Technical power losses caused mainly by the resistance of EPS components include losses in the transmission, subtransmission, distribution system components, and in the connection links from distribution to consumers. Transmission and Distribution losses in the developed countries are in range from 4-12\% [1, 2], while losses may increase to over $30 \%$ in other countries. Technical losses are possible to compute and control, provided the data of the concerned power system including load profile is available.

The value of power losses is one of the key indicators for quality of EPS operation. Operators of power systems make certain that the system is operating in or close to an optimal mode, so that the quality and reliability of supply to consumers are ensured. From the viewpoint of customers, the EPS should deliver electrical energy with high power quality in terms of voltage and frequency, high reliability, and minimal cost $[3,4,5,6]$. Moreover, the green house emissions of the generation system should be reduced according to international regulations [7]. 
Any variations in the power system configuration or in the load profile alongside the nonsymmetry and nonlinearities of EPS can cause deviation from the ideal optimal mode. This deviation results in add-on power losses and consequently additional operational cost of supplied electrical energy. To enhance this situation, the load bus voltages should be maintained within specified limits. This goal can be achieved by a set of actions such as controlling generators excitation, switching reactive power compensators, and adjusting on load line tap changer (OLTC) of grid transformers [8, 9, 10, 11].

This paper focuses on minimizing the add-on power losses and operational costs by adjusting the OLTC of grid transformers. The basis of the study methodology is the Design of Experiments (DOE) approach which helps to detect the impact of inputs-factors on the output-response while realizing the objectives. This statistical theory found its applications in many areas including EPSs [12].

\section{POWER LOSSES VERSUS CONTROL FACTORS}

To obtain the power losses $\Delta \boldsymbol{P}$ as a function of control parameters (for example OLTC setting of transformer $\boldsymbol{i}$ whose value corresponds to its turns ratio $\boldsymbol{K}_{\boldsymbol{i}}$ ), let us assume that the load profile of a power system is changed from $\boldsymbol{m}$-variant to $(\boldsymbol{m}+\boldsymbol{1})$ variant with optimal losses $\Delta \boldsymbol{P}_{o p \boldsymbol{t}}^{(\boldsymbol{m})}$ corresponding to $\boldsymbol{K}_{\boldsymbol{i} \text { opt }}^{(\boldsymbol{m})}$, and $\Delta \boldsymbol{P}_{o p t}^{(\boldsymbol{m}+\mathbf{1})}$ corresponding to $\boldsymbol{K}_{\boldsymbol{i} \text { opt }}^{(\boldsymbol{m}+\mathbf{1})}$, respectively. If the control parameters of the second mode $(\boldsymbol{m}+\mathbf{l})$ has some value $\boldsymbol{K}_{\boldsymbol{i}}^{(\boldsymbol{m + 1})}$ which is not the optimal factor, the losses would be $\Delta \boldsymbol{P}^{(\boldsymbol{m}+\mathbf{1})}$ leading to additional losses $\boldsymbol{\delta} \boldsymbol{P}_{\text {add }}^{(\boldsymbol{m}+1)}$ as follows:

$$
\delta P_{a d d}^{(m+1)}=\Delta P^{(m+1)}-\Delta P_{o p t}^{(m+1)}=\mathbf{f}\left(K_{i}^{(m+1)}-K_{i o p t}^{(m+1)}\right)
$$

In general equation (1) can be written as

$$
\delta P_{a d d i}=f\left(K_{i}\right)
$$

and, in terms of add-on operational cost, as:

$$
C_{a d d i}^{(m+1)}=\delta P_{a d d i}^{(m+1)} T_{(m+1)} * B
$$

where,

$\boldsymbol{\delta} \boldsymbol{P}_{\text {add } \boldsymbol{i}}^{(\boldsymbol{m}+\boldsymbol{1})}$ actual add-on powe losses for $(\boldsymbol{m}+\boldsymbol{1})$-mode for transformer $\boldsymbol{i}$

$\boldsymbol{T}_{(\boldsymbol{m}+\mathbf{1})}$ time duration of $(\boldsymbol{m}+\boldsymbol{1})$ load mode defined by the daily load profile

$B \quad$ cost of energy [USD $/ \mathrm{kWh}]$

From the above-mentioned equations, we can observe a relationship between add-on operational cost $\boldsymbol{C}_{\boldsymbol{a d d}}$ and the switching-steps number of each transformer $\boldsymbol{n}_{\boldsymbol{i}}$. This relation can be predicted by use of linear regression procedure based on data acquired from designed experiments.

\section{STATISTICALLY-DESIGNED EXPERIMENTS AND REGRESSION}

Experimental design is a statistical theory that addresses the design and analysis of experiments. In an experimental study, one or more factors (independent variables) are changed so that the factors influence another variable referred to as the (response variable), or simply the response is obtained. The data obtained by conducting the experiments is analyzed by regression. Regression analysis serves to identify the relationship between a dependent variable (response) and one or more independent variables (factors). A linear or nonlinear regression model of the relationship is hypothesized, and the regression coefficients are calculated using the experimental data and the least-square method to develop an estimated regression equation. Experimental data are then employed to determine if the model is satisfactory. If the model is found to be satisfactory, the estimated regression equation can be used to predict the value of the dependent variable's given values for the independent variables [13].

The polynomial regression model

$$
y_{k}=a_{0}+a_{1} x_{k}+a_{2} x_{k}^{2}+\ldots+a_{f} x_{k}^{f}+\varepsilon_{k}(k=1,2, \ldots, N)
$$


can be expressed in matrix form in terms of a design matrix $\mathbf{X}$, a response vector $\overrightarrow{\boldsymbol{y}}$, a parameter vector $\overrightarrow{\boldsymbol{a}}$, and a vector $\overrightarrow{\boldsymbol{\varepsilon}}$ of random errors. The $\boldsymbol{i}^{\boldsymbol{t h}}$ row of $\mathbf{X}$ and $\overrightarrow{\boldsymbol{y}}$ will contain the $\boldsymbol{x}$ and $\boldsymbol{y}$ values for the $\boldsymbol{i}^{\boldsymbol{t h}}$ data sample. Then the model can be written as a system of linear equations $[12,15,16]$ :

$$
\left[\begin{array}{c}
y_{1} \\
y_{2} \\
y_{3} \\
\vdots \\
y_{n}
\end{array}\right]=\left[\begin{array}{ccccc}
1 & x_{1} & x_{1}^{2} & \ldots & x_{1}^{f} \\
1 & x_{2} & x_{2}^{2} & \ldots & x_{2}^{f} \\
1 & x_{3} & x_{3}^{2} & \ldots & x_{3}^{f} \\
\vdots & \vdots & \vdots & & \vdots \\
1 & x_{n} & x_{n}^{2} & \ldots & x_{n}^{f}
\end{array}\right]\left[\begin{array}{c}
a_{0} \\
a_{1} \\
a_{2} \\
\vdots \\
a_{f}
\end{array}\right]+\left[\begin{array}{c}
\varepsilon_{1} \\
\varepsilon_{2} \\
\varepsilon_{3} \\
\vdots \\
\varepsilon_{n}
\end{array}\right]
$$

which when using pure matrix notation is written as

$$
\overrightarrow{\boldsymbol{y}}=X \overrightarrow{\boldsymbol{a}}+\overrightarrow{\boldsymbol{\varepsilon}}
$$

The vector of estimated polynomial regression coefficients (using ordinary least-squares method) is:

$$
\widehat{\vec{a}}=\left(\mathbf{X}^{\mathrm{T}} \mathbf{X}\right)^{-1} \mathbf{X}^{\mathrm{T}} \overrightarrow{\boldsymbol{y}}
$$

The final regression model fitting the experimental data is:

$$
\widehat{y}=\widehat{a} \mathbf{X}=\mathbf{X}\left(\mathbf{X}^{\mathrm{T}} \mathbf{X}\right)^{-1} \mathbf{X}^{\mathrm{T}} \boldsymbol{y}
$$

Equation (2) that shows add-on loss $\boldsymbol{\delta} \boldsymbol{P}_{\text {addi }}$ as a function of $\boldsymbol{K}_{\boldsymbol{i}}$ can be considered as a relation between add-on loss and switching step number of OLTC setting $\boldsymbol{n}_{\boldsymbol{i}}$ which can be determined as:

$$
n_{i}=\left|\frac{K_{i o}^{(m)}-K_{i o}^{(m+1)}}{K_{\text {step } i}}\right|
$$

where, $\boldsymbol{K}_{\text {step } \boldsymbol{i}}$ is position step of OLTC of transformer $\boldsymbol{i}$. With a suitable scaling of the vertical axis, Equation (2) can be written as $\boldsymbol{C}_{\boldsymbol{a d d} \boldsymbol{i}}=\mathbf{f}\left(\boldsymbol{K}_{\boldsymbol{i}}\right)$. The values of additional operational cost can be computed by running a power flow software for the EPS with various load modes and designed experiments concerning the sets of OLTC of transformers.

To apply a regression analysis, a regression model should first be selected. Regression models estimate $\boldsymbol{y}$ values for known $\boldsymbol{x}$ values. The second order polynomial regression model is selected as:

$$
\widehat{y}_{k}=a_{0}+a_{1} x_{k}+a_{2} x_{k}^{2}
$$

Using the least squares method, the normal equations are formulated as:

$$
\left[\begin{array}{ccc}
N & \sum_{k=1}^{N} x_{k} & \sum_{k=1}^{N} x_{k}^{2} \\
\sum_{k=1}^{N} x_{k} & \sum_{k=1}^{N} x_{k}^{2} & \sum_{k=1}^{N} x_{k}^{3} \\
\sum_{k=1}^{N} x_{k}^{2} & \sum_{k=1}^{N} x_{k}^{3} & \sum_{k=1}^{N} x_{k}^{4}
\end{array}\right]\left[\begin{array}{l}
a_{0} \\
a_{1}
\end{array}\right]=\left[\begin{array}{c}
\sum_{k=1}^{N} y_{k} \\
\sum_{k=1}^{N} x_{k} y_{k} \\
\sum_{k=1}^{N} x_{k}^{2} y_{k}
\end{array}\right]
$$

These normal equations have unique solutions provided that $\boldsymbol{x}_{\boldsymbol{k}}$ is distinct.

The curve fitting can be performed by Matlab using the toolbox cftool (xdata, $y$ data) which opens Curve Fitting Tool with data, factors $\boldsymbol{x d a t a}$ and $\boldsymbol{y d a t a}$. $\boldsymbol{x}$ data and $\boldsymbol{y}$ data must be vectors of the same size. The results include values of constants a's and the indicators of goodness of fit: $\mathbf{S S E}, \mathbf{R}^{2}$, adjusted $\mathbf{R}^{\mathbf{2}}$ and RMSE. 
The regression model in terms of factors and response of transformer $\boldsymbol{i}$ is represented as:

$$
\widehat{C}_{a d d, i k}=a_{0}+a_{1} n_{i k}+a_{2} n_{i k}^{2}
$$

where $\widehat{\mathbf{C}}_{\boldsymbol{a d d}, \boldsymbol{i} \boldsymbol{k}}$ and $\boldsymbol{n}_{\boldsymbol{i} \boldsymbol{k}}$ represent $\widehat{\boldsymbol{y}}_{\boldsymbol{k}}$ and $\boldsymbol{x}_{\boldsymbol{k}}$, respectively.

\section{CASE STUDY}

\subsection{Test Network}

The electrical network used in this study is given in Figure 1. It consists of 20 buses, 20 branches and 10 transformers, 5 of which are equipped with OLTCs.

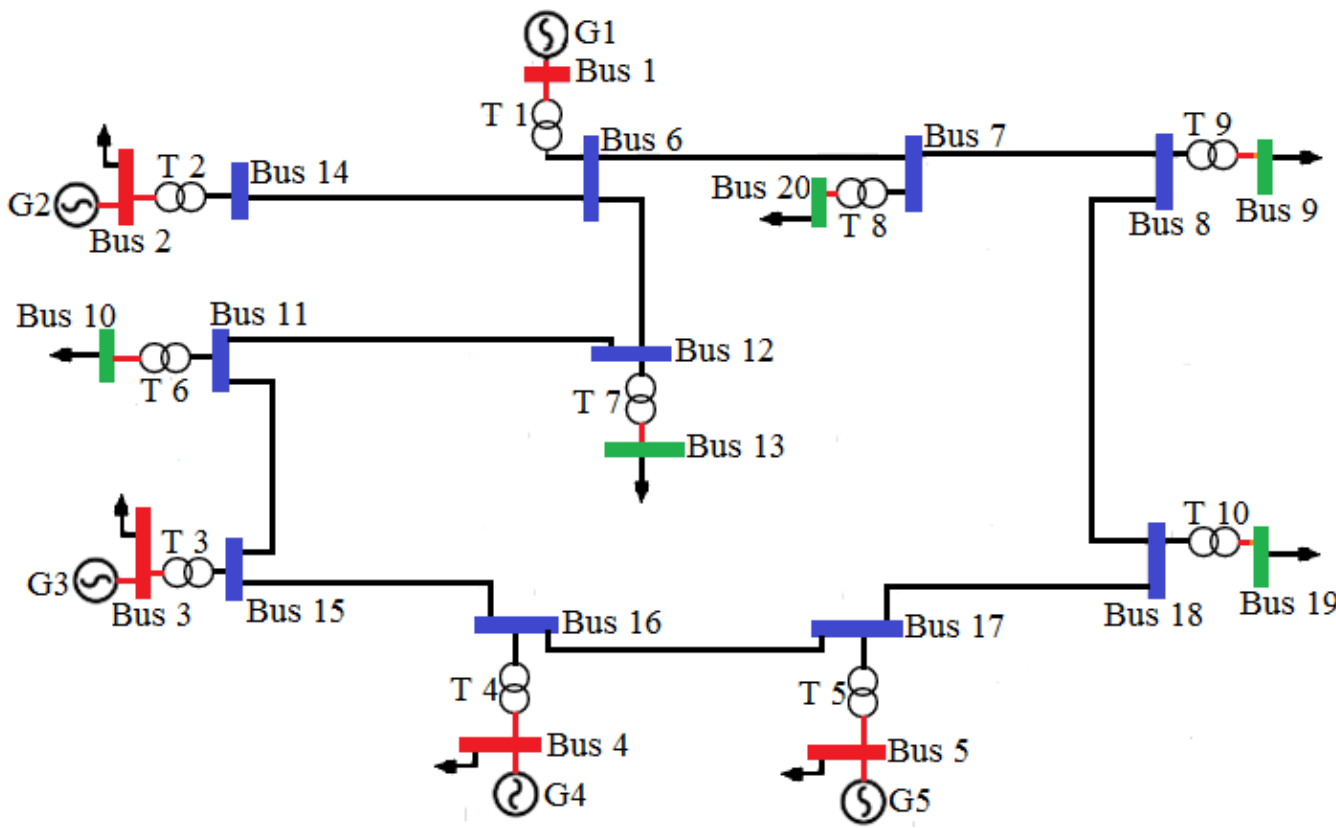

Figure 1. Single Line diagram of the test network

The input data are summarized in Tables 1, 2 and 3.

Table 1. Data of the 20-bus test network

\begin{tabular}{cccccc}
\hline Bus No. & PL (MW) & PG (MW) & Bus No. & PL (MW) & PG (MW) \\
\hline 1 & 0.00 & 0.00 & 11 & 0.00 & 0.00 \\
2 & 40.00 & 100.00 & 12 & 0.00 & 0.00 \\
3 & 45.00 & 100.00 & 13 & 40.00 & 18.60 \\
4 & 40.20 & 100.00 & 14 & 0.00 & 0.00 \\
5 & 30.00 & 100.00 & 15 & 0.00 & 0.00 \\
6 & 0.00 & 0.00 & 16 & 0.00 & 0.00 \\
7 & 0.00 & 0.00 & 17 & 0.00 & 0.00 \\
8 & 0.00 & 0.00 & 18 & 0.00 & 0.00 \\
9 & 36.20 & 16.50 & 19 & 70.00 & 26.60 \\
10 & 63.80 & 28.80 & 20 & 65.00 & 28.20 \\
\hline
\end{tabular}


Table 2. Branches data of test network

\begin{tabular}{ccccccc}
\hline \multirow{2}{*}{ Branch No. } & From Bus & To Bus & \multicolumn{2}{c}{ Series Impedance (p.u) } & Tap Setting & MVA Rating \\
\hline 1. & 1 & 6 & 0.00000 & 0.13000 & - & 500.00 \\
2. & 2 & 14 & 0.00000 & 0.11000 & - & 500.00 \\
3. & 3 & 15 & 0.00000 & 0.11000 & - & 500.00 \\
4. & 4 & 16 & 0.00000 & 0.11000 & - & 500.00 \\
5. & 5 & 17 & 0.00000 & 0.11000 & - & 500.00 \\
6. & 6 & 7 & 0.05700 & 0.17370 & - & 150.00 \\
7. & 6 & 12 & 0.04158 & 0.16144 & - & 150.00 \\
8. & 6 & 14 & 0.05300 & 0.12700 & - & 150.00 \\
9. & 7 & 8 & 0.03018 & 0.09196 & - & 150.00 \\
10. & 7 & 20 & 0.00000 & 0.12600 & 1.0681 & 100.00 \\
11. & 8 & 9 & 0.00000 & 0.12000 & 1.0681 & 80.00 \\
12. & 8 & 18 & 0.05091 & 0.15326 & - & 150.00 \\
13. & 11 & 10 & 0.00000 & 0.12600 & 1.0681 & 80.00 \\
14. & 11 & 12 & 0.06173 & 0.18596 & - & 150.00 \\
15. & 11 & 15 & 0.02079 & 0.06335 & - & 150.00 \\
16. & 12 & 13 & 0.00000 & 0.10740 & 1.0681 & 63.00 \\
17. & 15 & 16 & 0.02884 & 0.08787 & - & 150.00 \\
18. & 16 & 17 & 0.07376 & 0.22479 & - & 150.00 \\
19. & 17 & 18 & 0.06639 & 0.20231 & - & 150.00 \\
20. & 18 & 19 & 0.00000 & 0.12600 & 1.0681 & 100.00 \\
\hline
\end{tabular}

Table 3. Data of the transformers and modes losses

\begin{tabular}{|c|c|c|c|c|c|c|c|c|c|c|}
\hline Transformer No & 1 & 2 & 3 & 4 & 5 & 6 & 7 & 8 & 9 & 10 \\
\hline$K_{\text {step } i}$ & - & - & - & - & - & 0.0788 & 0.0788 & 0.0788 & 0.0788 & 0.0788 \\
\hline$K_{\text {step } o}$ & 0.1515 & 0.1515 & 0.1136 & 0.1136 & 0.1136 & 4.000 & 4.000 & 4.000 & 4.000 & 4.000 \\
\hline$K_{\text {step } 1}$ & - & - & - & - & - & 4.0788 & 4.0788 & 4.0788 & 4.0788 & 4.0788 \\
\hline$K_{\text {step } 2}$ & - & - & - & - & - & 4.1576 & 4.1576 & 4.1576 & 4.1576 & 4.1576 \\
\hline$K_{\text {step } 3}$ & - & - & - & - & - & 4.2364 & 4.2364 & 4.2364 & 4.2364 & 4.2364 \\
\hline$K_{\text {step } 4}$ & & & & & & 4.3152 & 4.3152 & 4.3152 & 4.3152 & 4.3152 \\
\hline$K_{\text {optimal }}$ & 0.1515 & 0.1515 & 0.1136 & 0.1136 & 0.1136 & 4.3949 & 4.3949 & 4.0000 & 4.0000 & 4.0000 \\
\hline $\begin{array}{cl}\Delta \boldsymbol{P}_{\boldsymbol{o}} ; & \text { MW } \\
\text { Mode } 2 \text { (Peak) }\end{array}$ & \multicolumn{10}{|c|}{19.565} \\
\hline $\begin{array}{c}\boldsymbol{D}_{\boldsymbol{i}} \\
\Delta \boldsymbol{P} ; \mathrm{MW}\end{array}$ & \multicolumn{10}{|c|}{31.68} \\
\hline
\end{tabular}

Figure 2 shows Load Mode ( $\boldsymbol{m})$-optimal and $(\boldsymbol{m}+\mathbf{1})$ - peak) power losses in MW, without proper tapping of the 5 transformers.

QLoad mode capacity; [\%] DPower system losses; [MW] QTime perio; [Hours]

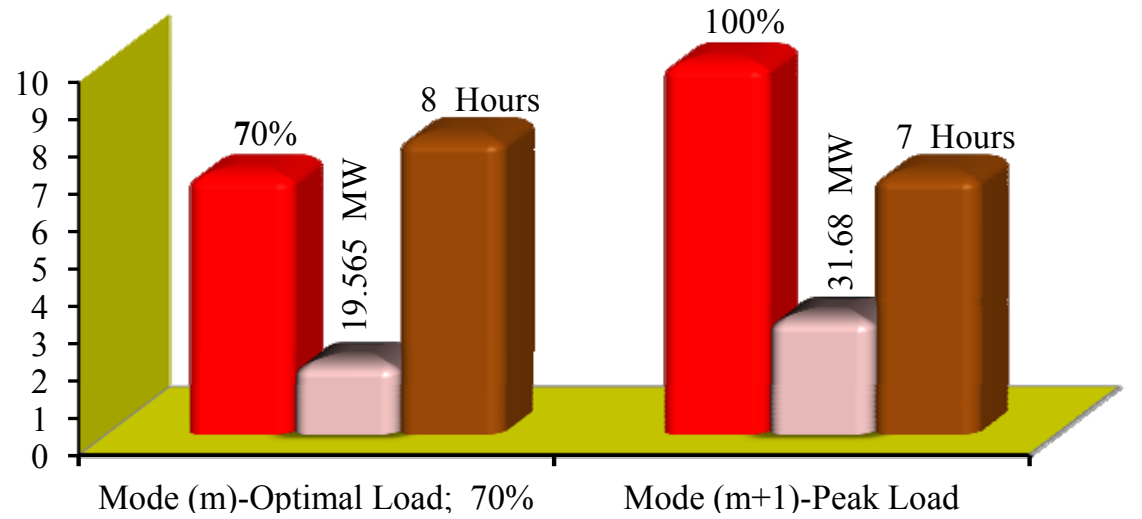

Figure 2. Power Losses of modes $\boldsymbol{m}$ and $(\boldsymbol{m}+\mathbf{1})$ Load varents 
The 5 single-factor test scenarios are shown in Table 4, from which the fitted regression curves are obtained by Matlab.

Table 4. Single-Factor Test Scenario for Load Mode $(\boldsymbol{m}+\boldsymbol{1})$

\begin{tabular}{|c|c|c|c|c|c|c|c|}
\hline Scenarios & $\begin{array}{c}\text { T6 } \\
\text { TC setting }\end{array}$ & $\begin{array}{c}\text { T7 } \\
\text { TC setting }\end{array}$ & $\begin{array}{c}\text { T8 } \\
\text { TC setting }\end{array}$ & $\begin{array}{c}\text { T9 } \\
\text { TC setting }\end{array}$ & $\begin{array}{c}\text { T10 } \\
\text { TC setting }\end{array}$ & $\begin{array}{c}\Delta \mathrm{P} \\
\mathrm{MW}\end{array}$ & $\begin{array}{c}\delta \mathrm{P} \\
\mathrm{MW}\end{array}$ \\
\hline 1 & 1 & 0 & 0 & 0 & 0 & 38.24 & 6.56 \\
\hline 2 & 2 & 0 & 0 & 0 & 0 & 35.46 & 3.78 \\
\hline 3 & 3 & 0 & 0 & 0 & 0 & 34.77 & 3.09 \\
\hline 4 & 4 & 0 & 0 & 0 & 0 & 34.08 & 2.40 \\
\hline 5 & 5 & 0 & 0 & 0 & 0 & 33.53 & 1.85 \\
\hline 6 & 0 & 1 & 0 & 0 & 0 & 39.86 & 8.18 \\
\hline 7 & 0 & 2 & 0 & 0 & 0 & 39.66 & 7.98 \\
\hline 8 & 0 & 3 & 0 & 0 & 0 & 39.57 & 7.89 \\
\hline 9 & 0 & 4 & 0 & 0 & 0 & 39.42 & 7.74 \\
\hline 10 & 0 & 5 & 0 & 0 & 0 & 39.21 & 7.53 \\
\hline 11 & 0 & 0 & 1 & 0 & 0 & 36.70 & 5.02 \\
\hline 12 & 0 & 0 & 2 & 0 & 0 & 34.49 & 2.81 \\
\hline 13 & 0 & 0 & 3 & 0 & 0 & 33.82 & 2.14 \\
\hline 14 & 0 & 0 & 4 & 0 & 0 & 33.44 & 1.76 \\
\hline 15 & 0 & 0 & 5 & 0 & 0 & 32.44 & 0.759 \\
\hline 16 & 0 & 0 & 0 & 1 & 0 & 39.68 & 8.00 \\
\hline 17 & 0 & 0 & 0 & 2 & 0 & 38.15 & 6.471 \\
\hline 18 & 0 & 0 & 0 & 3 & 0 & 36.12 & 4.439 \\
\hline 19 & 0 & 0 & 0 & 4 & 0 & 35.894 & 4.214 \\
\hline 20 & 0 & 0 & 0 & 5 & 0 & 34.63 & 2.95 \\
\hline 21 & 0 & 0 & 0 & 0 & 1 & 39.66 & 7.98 \\
\hline 22 & 0 & 0 & 0 & 0 & 2 & 39.16 & 7.48 \\
\hline 23 & 0 & 0 & 0 & 0 & 3 & 39.17 & 7.49 \\
\hline 24 & 0 & 0 & 0 & 0 & 4 & 39.18 & 7.50 \\
\hline 25 & 0 & 0 & 0 & 0 & 5 & 39.21 & 7.53 \\
\hline
\end{tabular}

From Figure 3 it is obvious that the transformers 7 and 10 have negligible effects on add-on operational costs, while the transformers 6,8 , and 9 are considered as critical components. Therefore, we check the multifactor scenarios of transformers 6,8 and 9 . The number of these scenarios should be $2^{\wedge} \mathbf{3}=\mathbf{8}$. The power flow for these scenarios result in values of power losses and add-on costs as shown in Table 5 .

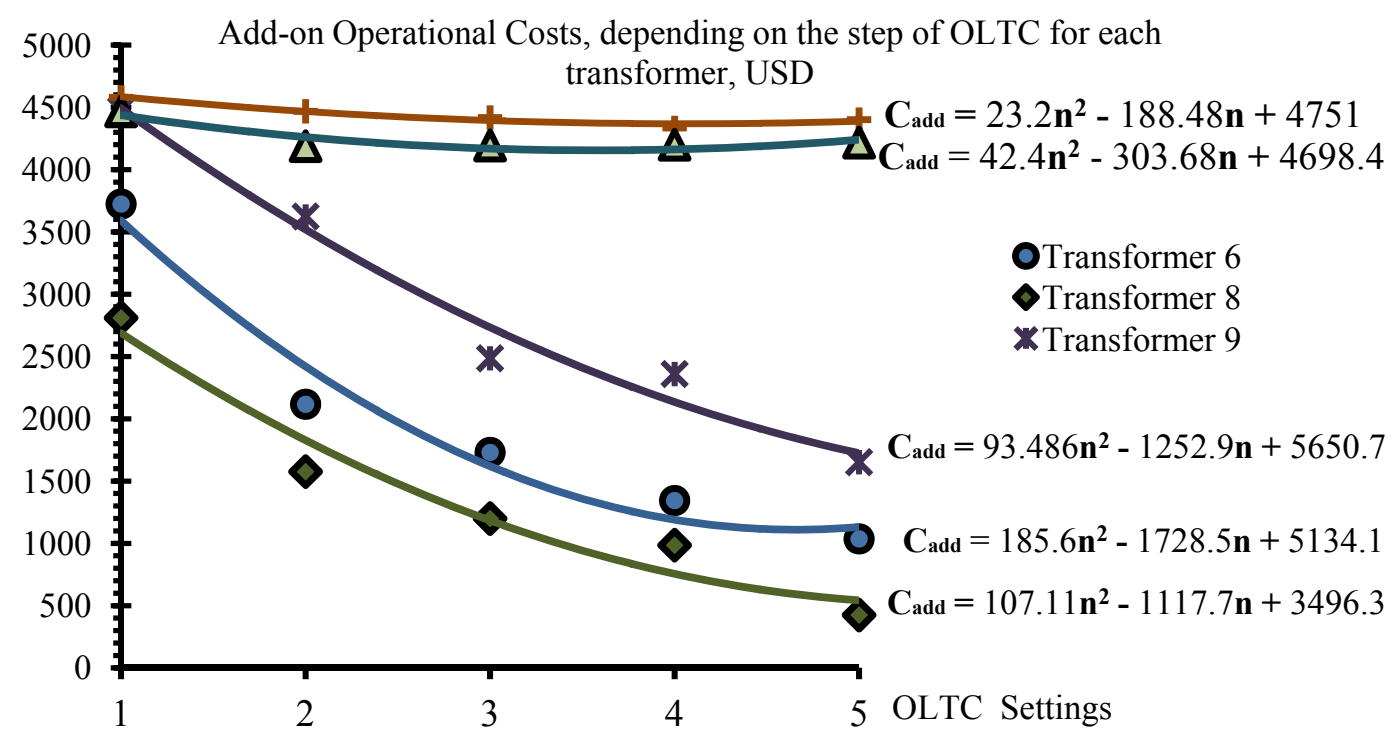

Figure 3. Fitted regression curves of the 5 single-factor test scenarios 
Table 5. Multifactor Test Scenarios for Load Mode $(\boldsymbol{m}+\mathbf{I})$

\begin{tabular}{cccccc}
\hline Scenarios No; & T6 & T8 & T9 & $\boldsymbol{\Delta P} ;$ MW & $\boldsymbol{\delta P} ;$ MW \\
\hline 1 & - & - & - & 44.425 & 12.745 \\
2 & + & - & - & 35.054 & 1.107 \\
3 & - & + & - & 38.444 & 6.764 \\
4 & - & - & + & 39.65 & 7.97 \\
5 & - & + & + & 37.85 & 6.17 \\
6 & + & + & + & 31.73 & 0.05 \\
7 & + & + & - & 32.207 & 0.527 \\
8 & + & - & + & 34.536 & 2.856 \\
\hline
\end{tabular}

Figure 4 shows Load flow results of power losses and add-on power losses of Multifactor Experiments for Load Mode $(\boldsymbol{m}+\mathbf{1})$ load.

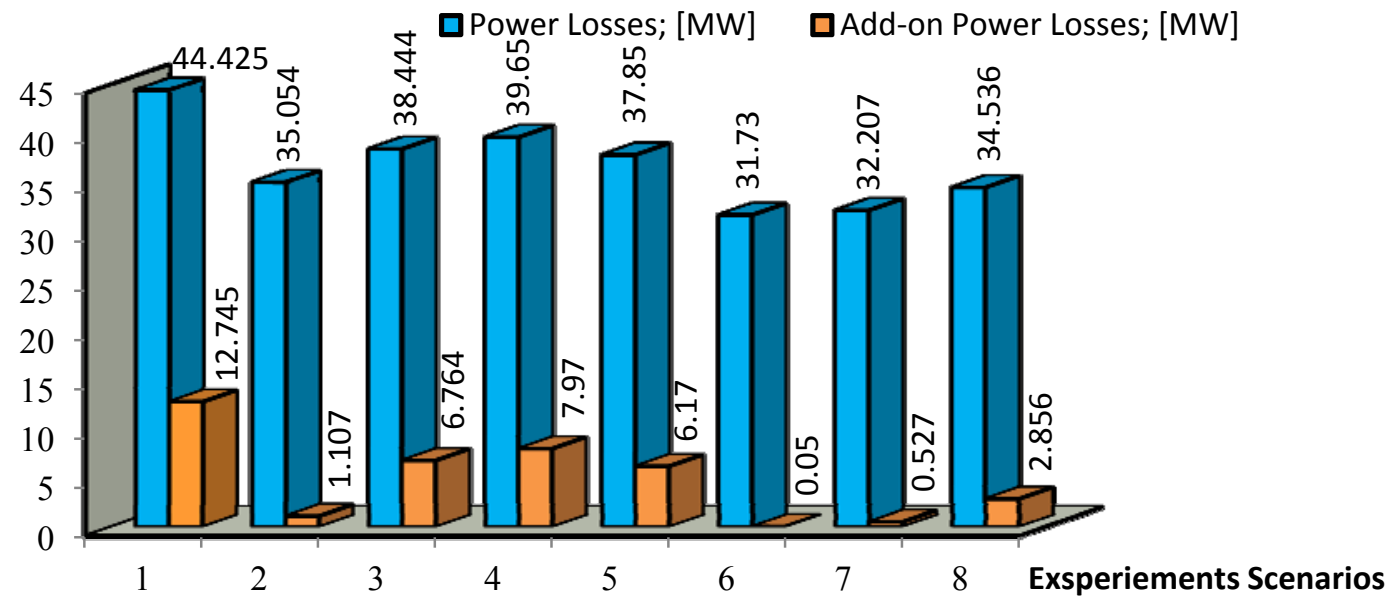

Figure 4. Load flow results of power losses and add-on power losses of Multifactor Experiments for Load Mode $(\boldsymbol{m}+1)$

The graphical chart of add-on operational losses and add-on operational costs of multi-factor test scenarios for Load Mode $(\boldsymbol{m}+1)$ is shown in Figure 5.

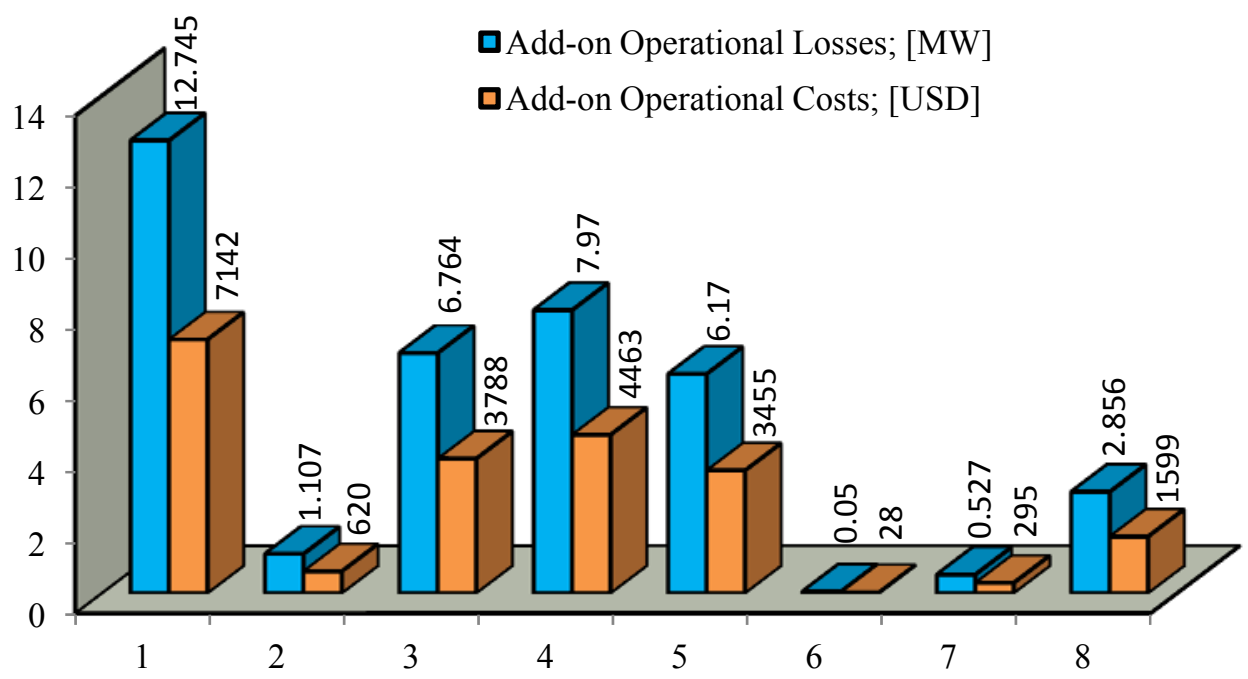

Figure 5. Add-on operational losses and add-on operational costs of multi-factor test scenarios for Load Mode $(\boldsymbol{m}+1)$ 
From Figure 5 it is obvious that the scenario 6 gives the minimum additional power losses of 0.05 MW and consequently the lowest add-on operational cost. This scenario dictates that the OLTC settings of all three transformers should be at the high position (Step 5).

\section{CONCLUSIONS}

The paper presents a mathematical model and an algorithm of minimizing the add-on operational real power losses and add-on operational cost in electrical power systems, based on Design of Experiments approach and polynomial linear regression. The model takes into consideration the control parameters of OLTC transformers. However, it can easily be extended to consider other control variables such as generator excitation levels, and VAR compensators switching. The developed model and algorithm should be beneficial for Distribution System Operator in detecting critical transformers and meeting proper tapping to minimize the power system add-on losses. The model has been successfully applied to a test network and the results obtained were examined and discussed.

\section{REFERENCES}

[1] J.P Navani1, N.K Sharma, Sonal Sapra, "Technical and Non-Technical Losses in Power System and Its Economic Consequence in Indian Economy", International Journal of Electronics and Computer Science Engineering, IJECSE, Vol. 2, Pages 757-761, 2012.

[2] Ali Nourai, V.I. Kogan and Chris M. Schafer, "Load Leveling Reduces T\&D Line Losses", IEEE Transactions on Power Delivery, Vol. 23 Issue: 4, Pages 2168 - 2173, 11 April 2008.

[3] A. Khazaee, M. Ghasempour, "Distribution Loss Minimization: A Case Study in a Commercial Section In Mashhad", 22nd International Conference and Exhibition on Electricity Distribution (CIRED 2013), Stockholm, 10-13 June 2013, Paper 0825

[4] R.F. Hirsh, "Power Loss: The Origins of Deregulation and Restructuring in the American Electric Utility System", MIT Press, Cambridge, MA and London, 1999.

[5] Al-Omari Z. and Abdallah J. Modeling Additional Operational Costs Incurred Due to Absent of the Optimal Correction in Electrical Systems. Journal of applied sciences, Volume 8, No. (23); Pages 4422-2227, 2008

[6] Al-Omari Z., "Influence of Control Modes of Grid-Connected Solar Photovoltaic Generation on Grid Power Flow", Engineering 6, Pages 914-922, 2014. http://dx.doi.org/10.4236/eng.

[7] C. Budischak, DeAnna Sewell, H. Thomson, L. Mach, D. E. Veron, W. Kempton, "Cost-minimized combinations of wind power, solar power and electrochemical storage, powering the grid up to $99.9 \%$ of the time", Journal of Power Sources, Elsevier 225, Pages 60-74, (2013). http://dx.doi.org/10.1016/j.jpowsour.2013.01.046.

[8] K.C. Mamandur, R.D. Chenoweth. "Optimal Control Of Reactive Power Flow For Improvements In Voltage Profiles And For Real Power Loss Minimization", IEEE Transactions on Power Apparatus and Systems, Vol. PASI1O, No. 7, Pages 3185-3194, July 1981

[9] Glavitsch, H. and R. Bacher, "Optimal Power Flow Algorithms. In Control and Dynamic Systems. Advances in Theory and Applications Vol. 41: Analysis and Control System Techniques for Electric Power Systems Part 1 of 4, Edited by C. T. Leonds, Pages 135-206. Academic Press, InC. 1991.

[10] Abdallah, J., "Distribution Network Planning and Design Using Branch and Bound Methods", American Journal of Applied Science, 2(3), Pages 644-647, 2005.

[11] Bakhshideh Zad B, Lobry J, Vallée F., "Coordinated control of on-load tap changer and D-STATCOM for voltage regulation of radial distribution systems with DG units", In: 3rd International conference on electric power and energy conversion systems, Istanbul, Turkey; October 2013.

[12] Jean-François Toubeau, François Vallée, Zacharie De Grève, Jacques Lobry, "A new approach based on the experimental design method for the improvement of the operational efficiency in Medium Voltage distribution networks, J.F.", Electrical Power and Energy Systems 66, Pages 116-124, (2015)

[13] Dennis J. Sweeney, "Statistics Science“, Encyclopedia Britannica http://www.britannica.com/EBchecked/topic/564172/statistics/60711/Experimental-design

[14] Wikipedia, the free encyclopedia

[15] W. Paul Vogt (Editor), Burke Johnson (Editor), R. (Robert) Burke Johnson(Editor), "Correlation and Regression Analysis", Sage Publications Ltd, 2012

[16] Ronald E. Walpole et al, "Probability \& Statistics for Engineers \& Scientists", Prentice Hall 2012 


\section{BIOGRAPHIES OF AUTHORS}

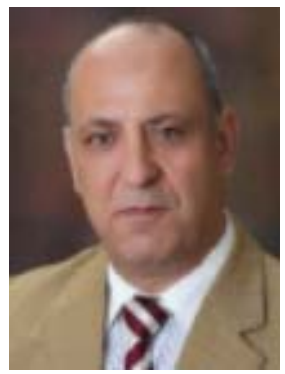

Zakaria Al-Omari, PhD.El.Eng. (IEEE M) was born in Irbid Jordan on June 3, 1966. He obtained his MSc degree (1991), in Electrical Engineering/Power fro the Faculty of Electrical Engineering, Vinnytsia State Polytechnic Institute, Ukraine and his PhD degree from the Faculty of Electrical Engineering, Vinnytsia State University, Ukraine in 1998. Currently he is an Assistant Professor at Electrical Engineering Department at Faculty of Engineering, Al-Ahliyya Amman University in Amman, Jordan. His main interests are minimizing of power system losses, renewable energy, load forecasting, reliability and efficiency. He has published 12 technical papers in Journals and international conferences. He is a Member of IEEE PES Society

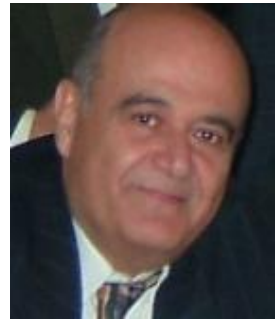

Ali Hamzeh, PhD.El.Eng. (IEEE M) was born in Syria. He received the B.Sc degree in Electrical Engineering from the Aleppo University, Syria and and his Ph.D degree in electrical engineering, from University of Dresden, Germany, in 19. Currently he is a Full Professor at Electrical Engineering Department at Faculty of Engineering, Al-Ahliyya Amman University in Amman, Jordan. His main interests are Power system security, Power system stability, Smart grids, Integration of Distributed Generations (wind and solar) into electric grid, Design and operation of Solar PV and Wind Turbine systems, Energy Efficiency and Environmental Protection and Operation \& Maintenance of conventional and renewable electric power systems. He has published 87 technical papers in Journals and international conferences. He is a Member of IEEE PES Society

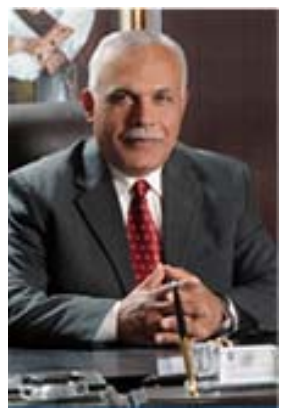

Sadeq Abdullah Hamed, he is the president of AAU since 2011, He received the B.Sc degree in Electrical Power Engineering from the Damascus University, M.Sc. in Power Electronics and Systems and Ph.D. in Power Electronics (AC Power Conditioning \& Electrical Machines Control) from the UMIST, UK. Prof. Hamed has published more than 25 research papers in highly-ranked journals and conferences. In addition to his long experience in the field of education as a university professor, locally and internationally, he has supervised many M.Sc Theses. Prof. Sadeq Hamed was the Vice-President for Academic Affairs \& Dean of the Faculty of Engineering at AAU, also as Dean of Faculty of Engineering Technology, Al-Balqa' Applied University, Vice Dean, of Faculty of Engineering and Technology and Chairman of the Department of Electrical Engineering, University of Jordan.

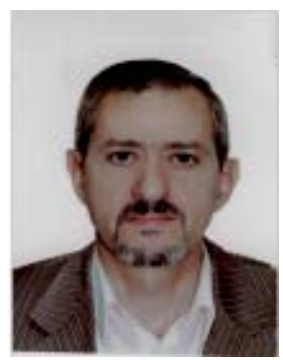

Abbas Sandouk received the B.Sc (1985), M.Sc. (1994) and Ph.D (1998) degrees in Electrical Power Engineering from Damascus University, Syria. He is currently an Associate Professor at Electrical Power Engineering Department at Faculty of Mechanical \& Electrical Engineering, Damascus University, Syria. He has published more than 10 peer-reviewed Journal and Conference papers. His main research interests are Electrical machines, Power systems, and Renewables energy systems. He is member of Syrian Engineers Society (SES), Energy Committee of SES-Branch Damascus, World Wind Energy Association (WWEA), and Arab Institute for Operation \& Maintenance in Arab Countries.

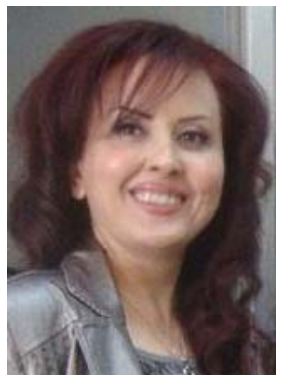

Ghada Aldahim recieved her B.Sc (1985), M.Sc. (2008) and Ph.D (2014) degrees in Electrical Power Engineering from Damascus University, Syria. She is currently a technical staff manager and lecturer at Electrical Engineering Department and Mechatronics Department at Damascus University, Syria. She has published 8 peer-reviewed Journal and Conference papers. Her research areas are Electrical Power Systems, Distributed Generation, Bifurcation \& Chaos Theory, Applications to DC-DC Converters, Renewable Energy Systems. She is member of Syrian Engineers Society (SES), Energy Committee of SES-Branch Damascus, World Wind Energy Association (WWEA), and Arab Institute for Operation \& Maintenance in Arab Countries. 